\title{
Proton Irradiation Creep of FM steel T91
}

Cheng Xu, Gary S. Was

University of Michigan, 2355 Bonisteel Blvd, Ann Arbor, MI 48109-2104, USA

\begin{abstract}
Ferritic-martensitic (FM) steel T91 was subjected to irradiation with $3 M e V$ protons while under load at stresses of $100 \mathrm{MPa}-200 \mathrm{MPa}$, temperatures between $400^{\circ} \mathrm{C}-500^{\circ} \mathrm{C}$, and dose rates between $1.4 \times 10^{-6} \mathrm{dpa} / \mathrm{s}-5 \times 10^{-6} \mathrm{dpa} / \mathrm{s}$ to a total dose of less than $1 \mathrm{dpa}$. Creep behavior was analyzed for parametric dependencies. The temperature dependence was found to be negligible between $400^{\circ} \mathrm{C}-500^{\circ} \mathrm{C}$, and the dose rate dependence was observed to be linear. Creep rate was proportional to stress at low stress values and varied with stress to the power 14 above $160 \mathrm{MPa}$. The large stress exponent of the proton irradiation creep experiments under high stress suggested that dislocation glide was driving both thermal and irradiation creep. Microstructure observations of anisotropic dislocation loops also contributed to the total creep strain. After subtracting the power law creep and anisotropic dislocation loop contributions, the remaining creep strain was accounted for by dislocation climb enabled by stress induced preferential absorption (SIPA) and preferential dislocation glide (PAG).
\end{abstract}

Keywords:

Creep, irradiation, ferritic martensitic steels, T91, transient creep.

Corresponding author: Cheng $\mathrm{Xu}$

University of Michigan

Phone: 7346213647

2355 Bonisteel Blvd, Ann Arbor

Email: chengxu@umich.edu

MI, 48109-2104 


\section{Introduction}

Ferritic-martensitic (F-M) steels have a number of attractive properties for use as cladding and ducts in sodium cooled fast reactors, including high strength at elevated temperatures, good compatibility with sodium coolant, and excellent swelling resistance under irradiation. At fast reactor operating temperatures, irradiation creep becomes a major concern. An understanding of the creep mechanism was required to determine the suitability of these steels for the intended application. A large body of work had been done to summarize the potential irradiation creep mechanisms that could occur in FM steels. [1]-[3] The majority of the recent efforts had been focused on the irradiation creep mechanisms of stress-induced preferential absorption (SIPA), [4]-[6], preferential absorption glide (PAG), [7], [8] and preferential emission (PE) at higher temperatures [8]. To determine the dominant irradiation creep mechanism in FM steels, more irradiation data were needed to clarify the dependence of creep on the various irradiation parameters and to link the irradiation creep microstructure to the measured creep strain for a detailed analysis.

Irradiation creep experiments in test reactors such as FFTF, EBRII, and HFIR [13] used pressurized tubes that were periodically removed to measure the dimensional changes as a function of time. These experiments provided valuable quantitative creep data under conditions similar to those during actual operation. However, neutron irradiations were too expensive and time consuming to fully explore the nuances of specific creep mechanisms. In addition, neutron irradiation creep experiments were not conducive to exploring the transient behavior of irradiation creep that act as a precursor 
to steady state behavior. Therefore, efforts to systematically narrow down the specific mechanisms of irradiation creep are still needed.

To provide additional insight into the mechanism of irradiation creep of FM steels, experiments were conducted using $3 \mathrm{MeV}$ protons generated by a linear accelerator. Creep behavior at low dose can be captured in real time at damage rates comparable to those of fast neutron irradiations. The instantaneous strain rates measured at low dose were analyzed to systematically explore the effect of single variables, such as dose rate, temperature, and stress. The measured irradiation creep rate parametric dependencies were analyzed in relation to existing irradiation creep theories. The low activation from proton irradiation also made post irradiation analysis easy to perform, providing a unique opportunity to capture microstructure during its evolution

This study explored the parameter dependencies of irradiation creep for FM steel T91 to obtain data that was used to differentiate between possible irradiation creep mechanisms such as preferential emission (PE), stress induced preferential absorption (SIPA), and preferential absorption glide (PAG). Proton irradiation creep experiments were conducted in the Michigan Ion Beam Laboratory (MIBL), and the irradiated samples were analyzed at the Electron Microbeam Analysis Laboratory (EMAL) at the University of Michigan, and the Nanotech User Facility (NTUF), at University of Washington. The results of the dose rate, temperature, and stress dependencies of irradiation creep are discussed along with its implications for existing irradiation creep theories.

\section{Experiment}


The composition of the T91 heat used in this experiment is given in Table 1. The as-received T91 plate was normalized at $1040^{\circ} \mathrm{C}$ for 46 minutes, followed by air cooling, then tempering at $760^{\circ} \mathrm{C}$ for 42 minutes. The samples were made by electric discharge machining into a dog-bone shape with a thickness of $100 \mu \mathrm{m}$, as shown in Figure 1. The samples were electro-polished in a $10 \%$ percholoric acid, and $90 \%$ methanol solution at $40^{\circ} \mathrm{C}$. An applied voltage of $20 \mathrm{~V}$ produced a current density of $2 \mathrm{~A} / \mathrm{cm}^{2}$. The average removal rate of this electro-polishing method was $20 \mu \mathrm{m} / \mathrm{min}$, and the samples were polished to a final thickness of $35 \pm 2 \mu \mathrm{m}$ to ensure full penetration of the $3 \mathrm{MeV}$ protons. The damage profile of SRIM simulation is illustrated in Figure 2. The damage profile was fairly flat at an average of $5.6 \times 10^{-5}$ displacements/angstrom-ion, with the exception of last $2 \mu \mathrm{m}$ in the back where the damage was factor of 5 higher than the rest of the sample thickness. Because the higher damage was limited to a thin region close to the surface where radiation damage was unlikely to accumulate, the difference in damage was not expected to adversely affect the bulk irradiation creep. For the purpose of this study, the dose rate was calculated using the average damage profile across the sample thickness.

Irradiation creep experiments were conducted in a specially made irradiation creep stage described in a previous paper by $\mathrm{Xu}$ and Was [9]. Irradiations were conducted using $3 \mathrm{MeV}$ protons, which have a penetration distance of $40 \mu \mathrm{m}$ in stainless steel, to ensure that there was no implantation within the $35 \mu \mathrm{m}$ sample. The experimental setup, shown in Figure 3, had the capability for in-situ strain measurements for a dogbone sample under uniaxial tensile stress, high temperature, and proton irradiation. The strain rate measured by each irradiation creep experiment was obtained by taking the 
linear fit of the strain over time as measured by a laser speckle extensometer in the gage length. The irradiation temperature were monitored by a 2D thermal imager, and applied stress monitored by a load cell.

Seventeen irradiation creep experiments in total were conducted between $400^{\circ} \mathrm{C}$ to $500^{\circ} \mathrm{C}$, at dose rates between $1.4 \times 10^{-6}$ and $5 \times 10^{-6} \mathrm{dpa} / \mathrm{s}$ (as determined by SRIM Kinchin-Pease Mode [10]) to doses of $<1$ dpa and under loads of $100-200$ MPa. The strain rate data were analyzed as a function of dose rate, temperature, and stress. Error in the irradiation creep strain rates was determined by repeated experiments under the same conditions and on two samples, designated A and B. The thermal creep test condition of $500^{\circ} \mathrm{C}$ at 200MPa (TT500200-A and TT500200-B) was repeated, and two irradiation creep test conditions, $450^{\circ} \mathrm{C}$ at $200 \mathrm{MPa}$ (IT450200-A and IT450200-B) and $450^{\circ} \mathrm{C}$ at 180MPa (IT450180-A and IT450180-B) were also repeated. The calculated standard errors were found to vary between $29.4 \%$ to $50.5 \%$ of the measured creep rates. The largest percentage error was chosen as a conservative estimate of the error from repeated experiments for all measured creep rates.

Microstructure analysis of the irradiation creep samples was conducted using JOEL 3100 and Tecnai G2 transmission electron microscopes (TEM) to obtain information on the orientation of dislocation loops. The TEM samples were made using focused ion beam (FIB) milling to lift out a sample that preserved the tensile axis orientation as shown in Figure 1. Samples were imaged in the $<001>$ zone axis under a two-beam condition with $\mathrm{g}=<110>$ such that two sets of edge-on $\mathrm{a}_{0}<100>$ loops were visible. The angle $\theta$ between the normal vector of the dislocation loop plane and the tensile axis was used to define the loop orientation as shown in Figure 4. The number of 
dislocation loops of the two sets of edge-on loops were measured as a function of the loop orientation to the tensile axis to quantify its anisotropy.

\section{Results}

Seventeen irradiation creep experiments were conducted for this study at various temperature, stress, and dose rate conditions. The typical irradiation creep strain over time data is shown in Figure 5. The sample temperature, applied load, dose rate, and sample strain were all continuously monitored throughout the irradiation. Strain rates were calculated from line fits to the strain over time where temperature, dose rate, and stress were kept constant. The strain rates measured for each condition are tabulated in Table 2. The strain rates measured were then analyzed as a function of their dose rate, temperature, and stress dependence.

\subsection{Dose Rate Dependence}

An experiment was conducted on sample IT500160 to explore the dose rate dependence at $500^{\circ} \mathrm{C}$ and $160 \mathrm{MPa}$ in real time, taking advantage of the in-situ strain measurement capability of the facility. A high irradiation temperature was necessary to accommodate for the large range of beam heating required for the different dose rates. Three dose rate conditions were used in this experiment: $1.5 \times 10^{-6} \mathrm{dpa} / \mathrm{s}, 1.7 \times 10^{-6} \mathrm{dpa} / \mathrm{s}$, and $2.4 \times 10^{-6} \mathrm{dpa} / \mathrm{s}$. The corresponding strain rates were found to be $1.78 \pm 0.89 \times 10^{-9} \mathrm{~s}^{-1}$, $2.33 \pm 1.67 \times 10^{-9} \mathrm{~s}^{-1}$, and $5.08 \pm 2.54 \times 10^{-9} \mathrm{~s}^{-1}$. The strain rates are plotted against the dose rates in Figure 6. The data point at a dose rate of zero is the measured thermal creep rate at that temperature and the fit includes the data through these four points. A linear fit to 
the dose rate data fall within the experimental errors, suggesting the possibility of a linear dose rate dependence. The implication of a linear dose rate dependence and alternative dose rate dependencies are addressed in detail in the discussion section.

\subsection{Temperature Dependence}

Irradiation creep experiments were conducted at $400^{\circ} \mathrm{C}, 450^{\circ} \mathrm{C}$, and $500^{\circ} \mathrm{C}$ at $160 \mathrm{MPa}$ to explore the temperature dependence. The dose rate was maintained at the nominal value of $1.7 \times 10^{-6} \mathrm{dpa} / \mathrm{s}$ with the exception of the $400^{\circ} \mathrm{C}$ experiment where a lower dose rate of $1.3 \times 10^{-6} \mathrm{dpa} / \mathrm{s}$ was needed to maintain the temperature. The strain rates measured for the experiments at $400^{\circ} \mathrm{C}, 450^{\circ} \mathrm{C}$, and $500^{\circ} \mathrm{C}$ were $2.9 \pm 1.45 \times 10^{-9} \mathrm{~s}^{-1}$, $2.7 \pm 1.35 \times 10^{-9} \mathrm{~s}^{-1}$, and $2.33 \pm 1.17 \times 10^{-9} \mathrm{~s}^{-1}$ respectively. Because the creep rate measured at $400^{\circ} \mathrm{C}$ was conducted at a slightly lower dose rate, extrapolation of the $400^{\circ} \mathrm{C}$ strain rate

to $1.7 \times 10^{-6} \mathrm{dpa} / \mathrm{s}$ was calculated using the dose rate dependence at $500 \mathrm{C}$. The resulting strain rate was $2.93 \times 10^{-9} \mathrm{~s}^{-1}$. The strain rates are plotted as a function of temperature shown in Figure 7. The proton irradiation creep rates exhibited no temperature dependence.

\subsection{Stress Dependence}

To determine the stress dependence of irradiation creep, seven experiments were conducted at a constant temperature of $450^{\circ} \mathrm{C}$ and a dose rate of $1.7 \times 10^{-6} \mathrm{dpa} / \mathrm{s}$. The applied stress ranged from $100 \mathrm{MPa}$ to $200 \mathrm{MPa}$ at $20 \mathrm{MPa}$ intervals. The stress dependence of irradiation creep is shown in Figure 8. The creep rate dependence on stress 
appeared linear below 160MPa; but above that value, the creep rate increased rapidly with stress, indicating a high stress exponent.

Determination of the stress exponent in both stress regimes was done recursively by minimizing the residuals of the curve fit to the data, assuming the following form of the creep rate dependence:

$$
\dot{\varepsilon}=B_{I} \sigma^{n_{I}}+B_{T} \sigma^{n_{T}}
$$

where $B_{I}$ is an effective irradiation creep compliance, $\sigma$ is the applied stress, and $n_{I}$ is the irradiation creep stress exponent. Similarly, $B_{T}$ is the effective thermal creep compliance, $\sigma$ is the applied stress, and $n_{T}$ is the thermal creep stress exponent. The best fit for the data yield the following constants: $n_{I}=0.86, B_{I}=3.2 \times 10^{-11} \mathrm{~s}^{-1} \mathrm{MPa}^{-0.86}, n_{T}=14$, and $B_{T}=5.4 \times 10^{-}$

${ }^{41} \mathrm{~s}^{-1} \mathrm{MPa}^{-14}$. Separately, the irradiation and thermal creep describe the asymptotic behavior of the data, with irradiation creep at low stress and thermal creep at high stress. By taking the summation of both fits, the total irradiation creep rates are described by the following equation:

$$
\dot{\varepsilon}=3.2 \times 10^{-11} \sigma^{0.86}+5.4 \times 10^{-41} \sigma^{14}
$$

\subsection{Microstructure}

The loop microstructures of four irradiation creep experiments were analyzed in TEM. The major effect of irradiation was the formation of dislocation loops for which the number density varied with orientation. The loops were predominantly of the $\mathrm{a}_{\mathrm{o}}<100>$ type. Figure 9 shows representative TEM images from the four irradiation creep samples. In order to make appropriate comparisons between the loop densities from different grains, the loop number density for each orientation of $\mathrm{a}_{\mathrm{o}}<100>$ loops was normalized by 
the total number of $a_{o}<100>$ loops in that grain. The anisotropy in the loop density was defined by the fraction of one set of $a_{o}<100>$ loops over the entire $a_{0}<100>$ loop population of that grain. This normalized dislocation loop density is plotted against angle $\theta$ for all samples in Figure 10. Due to the small loop size of the $a_{0} / 2<111>$ loops, they were not analyzed in this study. The measurements showed that there was strong anisotropy in the $a_{0}<100>$ dislocation loop density, in favor of loops that add extra half planes in the direction of the tensile stress. There was no anisotropy in the loop size, and no voids were observed in any of the samples.

The strain due to the loop anisotropy for each sample was calculated using an equation developed by Kroupa [11] assuming a continuous distribution of interstitial loops. The result of the calculations are summarized in Table 3 . The strain contribution from loop anisotropy in the tensile direction was found to be responsible for $4-11 \%$ of the total measured creep strain. Details of the calculations were described in a previous paper by $\mathrm{Xu}$ and Was [12].

\section{Discussion}

Several key observations were made as the result of this study. Dose rate dependence of irradiation creep was found to be linear, temperature dependence of irradiation creep was found to be negligible between $400^{\circ} \mathrm{C}-500^{\circ} \mathrm{C}$, and stress dependence of irradiation creep at $450^{\circ} \mathrm{C}$ was best described by an approximately linear stress dependence at low stress and a large stress exponent at high stress. Irradiation creep microstructure consisted of anisotropic distribution of dislocation loops. These 
results are discussed in comparison to previous irradiation creep observations for FM steels and irradiation creep mechanisms.

\subsection{Dose Rate Dependence}

The linear dose rate dependence observed for proton irradiation creep is generally expected in irradiation creep of FM steels. Chen [13], [14] normalized the strain rates of ferritic ODS alloys irradiated by light ions from a compact cyclotron to obtain creep compliance by assuming a linear dose rate dependence. Chin [15] also assumed a linear dose rate dependence for HT9 irradiated in EBRII. Although there are no neutron irradiation creep experiments specifically targeting the dose rate dependence of FM steels, Grossbeck [16] conducted irradiation creep experiments for three cold-worked austenitic steels irradiated in different mixed spectrum reactors for various dose rates. The slope of the fits on a log scale was approximately 0.5 in all cases, suggesting a square root dose rate dependence for neutron irradiated austenitic steels.

The difference between the dose rate dependence of austenitic steels and FM steels is due to the difference in their steady state point defect concentrations. Depending on the total sink density, the point defect concentrations can exhibit either a linear dependence or a square root dependence [17]. When the recombination of behavior of point defects dominates, the steady state defect concentration has a square root dependence on dose rate. In the sink dominant regime, the steady state defect concentration varies linearly with dose rate.

Characterization of the irradiated microstructure for T91 yields a total sink strength of $7.15 \times 10^{15} \mathrm{~m}^{-2}$ by accounting for sub-grain boundaries, dislocation loops, 
dislocation lines, and incoherent precipitates for sample IT450200, Table 4. The observed high sink densities of FM steels result in a much shorter time constant for interstitials to reach sinks vs. recombining with vacancies. The result is a sink dominant case that is consistent with the roughly linear dose rate dependence. By contrast, the sink density in austenitic stainless steels is expected to be much lower due to the relatively uncomplicated microstructure. Therefore, a square root dependence on dose rate is reasonable for this austenitic alloys.

Proton irradiation creep experiments at various dose rates suggest a linear dose rate dependence for FM steel T91. Analysis of the sink densities based on irradiation creep microstructure provided more evidence in support of that claim. The results of this study showed that dose rate dependence of irradiation creep experiments are effected by the microstructure, and provided supporting evidence for the historical assumption that FM steels exhibit a linear dose rate dependence. [13], [14]

\subsection{Temperature Dependence}

Temperature dependence of proton irradiation creep was consistent with existing observations from reactor irradiations [1]-[3], [13], [18]. Figure 11 plots the strain rates observed for a set of 9Cr-1Mo pressurized tube experiments conducted by Tolockzo [18] in FFTF along with the proton irradiation creep rates. The reactor irradiation creep strain rates found below $500^{\circ} \mathrm{C}$ appeared to have a small negative temperature dependence similar to those found in this study. However, the difference in the strain rates were small enough that the temperature dependence of irradiation creep can be considered to be negligible. 
Although the temperature dependence of proton irradiation creep rates match very well to those of neutrons, the magnitude of the strain rates were much higher. Under fast reactor conditions, the minimum creep rate for FM steels at $400-433^{\circ} \mathrm{C}$ for $100 \mathrm{MPa}$ was observed to be about $7 \times 10^{-6} \mathrm{dpa}^{-1}$. Assuming the average dose rate of $1 \times 10^{-6} \mathrm{dpa} / \mathrm{s} \mathrm{in}$ reactor, this corresponds to a creep around $7 \times 10^{-12} \mathrm{~s}^{-1}$. [18] Proton irradiations at $450^{\circ} \mathrm{C}$ and $100 \mathrm{MPa}$ at dose rate of $1.7 \times 10^{-6} \mathrm{dpa} / \mathrm{s}$ yielded a creep rate of about $1.67 \times 10^{-9} \mathrm{~s}^{-1}$. This difference persists if the creep rates are normalized by stress and dose rate to get a creep compliance, $B$. At $500^{\circ} \mathrm{C}$, assuming no contribution from irradiation swelling due to the low dose, $B_{\mathrm{o}}$ for proton irradiation creep is on the order of $1 \times 10^{-5} \mathrm{MPa}^{-1} \mathrm{dpa}^{-1}$, while neutron irradiation creep compliance are around $0.5 \times 10^{-6} \mathrm{MPa}^{-1} \mathrm{dpa}^{-1} \cdot[19]$ This large difference in strain rate is likely due to differences between neutron and proton irradiation creep experiments.

FM steels follow a three stage creep curve with a very short secondary regime. Neutron irradiation creep experiments typically report the minimum creep rate, measured at doses above $100 \mathrm{dpa}$. In contrast, proton irradiation creep rates were measured at a dose of less than $1 \mathrm{dpa}$ in the primary creep regime. At low dose, the microstructure has yet to develop, and the fewer obstacles against dislocation movement will result in higher strain rates compared to a steady state microstructure. However, the difference in microstructure alone is insufficient to explain the factor of $\sim 100$ difference in creep rate between neutron and proton data. The small thickness of the proton irradiation creep samples resulted in a large surface area to volume ratio and could have also contributed to the difference in strain rate. A larger surface area to volume ratio allows dislocations a shorter path to the surface without many prior austenite grain boundaries in the way to act 
as obstacles. This could magnify the effect of certain processes that would otherwise be considered negligible, such as thermal creep at below $500^{\circ} \mathrm{C}$.

Finally, the difference in damage morphology between neutrons and protons can also add to the difference in the measured creep rate. For a $1 \mathrm{MeV}$ neutron, the effective survival rate of the point defects are around $2 \%$ while for a $1 \mathrm{MeV}$ proton, it is around 25\%. [17] Thus, a higher percentage of point defects survived in proton irradiation experiments than in reactor experiments beyond the differences in dose rates. It has been shown in the dose rate analysis that strain rates are directly related to the point defect concentrations in the material, therefore a higher surviving point defect concentration also contribute to the higher strain rates seen in proton irradiation creep in comparison to neutron irradiations. Further, the larger damage zones created by neutrons vs. protons will contribute to the greater obstacle field in the case of reactor irradiations.

Due to the difference in creep regime, damage morphology, and sample thickness, proton irradiation creep experiments were not directly comparable to neutron data. However, because the differences were consistent in magnitude across all temperature, dose rate, and stress conditions, comparison of parameter dependencies and microstructure features is still valid.

\subsection{Stress Dependence}

The complex stress dependence found for this study was not typically observed in neutron irradiation creep experiments, where a single stress exponent of magnitude $\sim 1.0$ was typically used to fit the creep rate [18], [20]. Figure 12 plots the proton irradiation creep rates with the neutron irradiated data using the dose rate dependence in Figure 5 to 
extrapolate the damage rates to that of the reactor case. The open symbols represent literature data, and filled data are the results of this study. The dependence on stress over the same stress range is very similar for both irradiations, but the proton irradiation creep rate was about a factor of 100 higher due to the difference in dose and sample thickness discussed earlier.

The high stress exponent observed for proton irradiation creep at stresses above $160 \mathrm{MPa}$ was beyond what was measured in neutron irradiation creep experiments. However, a power law exponent of 10 or more was consistently observed in thermal creep of T91 at high stress [21], [22]. This power law breakdown (PLB) behavior has been well documented in the literature [23]. The power law stress dependence suggests that the creep rate is controlled by dislocation glide in the presence of long range internal stress, caused by dislocation networks generating back stress to impede further dislocation glide. Studies on thermal creep behavior show that materials typically enter PLB at stresses above half the yield stress [22], [24]. The yield strength of FM steels at $450^{\circ} \mathrm{C}$ was found to be around $400 \mathrm{MPa}$ [25], therefore PLB should be operating at stresses near 200MPa. The observation of PLB suggested that thermal dislocation creep mechanisms can occur in tandem with irradiation creep at high stress, obscuring the stress dependence of purely irradiation creep mechanisms.

To isolate the irradiation creep strain, the strains predicted by the power law fit (shown as green dashed line in Figure 8) were subtracted from the total strain. To further isolate the creep strains, the contribution from the anisotropic dislocation loop distribution was subtracted from the total measured creep strain. Although no anisotropic loop strain data was available for the $120 \mathrm{MPa}, 140 \mathrm{MPa}$, and $160 \mathrm{MPa}$ conditions, 
interpolation of the anisotropic loop strain between the 100MPa (IT450100) and $180 \mathrm{MPa}$ (IT450180) conditions was used to estimate those values.

The remaining irradiation creep strains could be due to three irradiation creep mechanisms: preferential emission (PE), stress induced preferential absorption (SIPA), or preferential absorption glide (PAG). Each irradiation creep mechanism has its own unique temperature and stress dependence. The results of the experiments were analyzed to determine the most likely mechanism dominating the irradiation creep.

\subsection{Irradiation Creep Mechanism}

Preferential emission (PE)

$\mathrm{PE}$ is a creep mechanism in which dislocations with Burgers vectors oriented parallel to the tensile axis emit more vacancies than those oriented perpendicular to the tensile axis. [8], [26]. The unequal vacancy emission causes anisotropic dislocation climb that ultimately results in creep strain. Because PE is largely a thermal diffusion mechanism based on the anisotropic emission of vacancies, it becomes rate controlling when thermal defects overtake irradiation defects. Calculations of the defect concentrations for T91 were conducted using point defect balance equations for the sink dominant regime [17]:

$$
C_{i}=\frac{K_{o}}{K_{i s} C_{s}}, \quad C_{v}=\frac{K_{o}}{K_{v s} C_{s}}
$$

where $K o$ is the dose rate, $K_{i s}$ and $K_{v s}$ are the total reaction rates to sinks, and $C_{s}$ the total sink density. The sink strength include sub-grain boundaries, dislocation networks, dislocation loops, and precipitates. Gupta and Was [27] showed that sub-grains, being the smallest grain feature in FM steels, can greatly affect creep behavior. Therefore, the sub- 
grain densities were measured by using line intercept method where interceptions between test lines and sub-grain boundaries were counted to arrive at an average subgrain diameter. The diameter was then used to calculate a volumetric sub-grain density that serves as the sink strength contribution from sub-grain boundaries. The precipitate measurements were taken from a proton irradiated $\mathrm{T} 91$ at $400^{\circ} \mathrm{C}$ to $1 \mathrm{dpa}$ without stress [28]. The precipitates measured from that study were largely incoherent $\mathrm{M}_{23} \mathrm{C}_{6}$ carbides on PAG boundaries, therefore they serve as neutral sinks [29]. Capture of defects by dislocations was in the diffusion-controlled regime. Values of sink concentrations and reaction rates are given in Table 4 .

The point defect concentrations of T91 as a function of temperature are shown in Figure 13. The calculation shows that thermal vacancies will dominate at temperatures above $540^{\circ} \mathrm{C}$, where the temperature dependence will start to increase. This behavior has also been observed in irradiation creep of other FM steels such as HT9 [15], [30] and F82H [31]. Proton irradiation creep experiments on T91 were conducted at and below $500^{\circ} \mathrm{C}$, where point defect concentrations are controlled by irradiation. The lack of a dependence of creep on temperature at $\mathrm{T} \leq 500^{\circ} \mathrm{C}$ confirms that $\mathrm{PE}$ is not the rate controlling mechanism for proton irradiation creep below $500^{\circ} \mathrm{C}$.

Stress Induced Preferential Absorption (SIPA) and Preferential Absorption Glide (PAG)

The dose rate dependence of irradiation creep suggests that it is directly related to the point defect concentrations under irradiation. Analysis on the temperature dependence of irradiation creep eliminated PE, a thermal vacancy diffusion mechanism, as a dominating mechanism. The subtraction of the PLB contribution from the total strain also 
removed strain due to vacancy enabled dislocation climb glide. The remaining creep strain is then likely to be due to either SIPA or PAG.

SIPA is a process in which dislocations with Burgers vectors oriented parallel to the tensile axis absorb more interstitials than those perpendicular to it. The anisotropic absorption allows dislocation climb preferentially on planes perpendicular to the tensile axis, thus adding more extra-half planes in the tensile direction to cause strain. Woo [4], [5] proposed that the climb of the existing anisotropic dislocation microstructure would also contribute irradiation creep strain even in the absence of anisotropic diffusion. Mansur [8] expanded on the SIPA mechanism by proposing that dislocations can also glide after preferential climb. SIPA and PAG were described by Mansur [8] as:

$$
\begin{aligned}
& \dot{\varepsilon}_{P A G}=\frac{4}{9} \frac{\epsilon}{b}(\pi L)^{1 / 2} \Omega D_{i} C_{i} \Delta Z_{i}, \\
& \dot{\varepsilon}_{S I P A}=\frac{2}{9} \Omega \mathrm{L} D_{i} C_{i} \Delta Z_{i} .
\end{aligned}
$$

The variable denotes elastic deflection, which is the applied stress over the modulus $\sigma / E, L$ is the total dislocation density, $\Omega$ is the atomic volume, $D_{i}$ is the interstitial diffusion constant, and $C_{i}$ is the steady state interstitial concentration. $\Delta Z_{i}$ is the difference in stress induced anisotropic sink strength for interstitials between aligned and unaligned sinks such that $\Delta Z_{i}=Z_{\text {aligned }}-Z_{\text {unaligned. }}$ The sink strengths are a linear function of stress as derived by Savino [25]:

$$
\begin{aligned}
& Z_{\text {aligned }}=z_{i}\left(1+\frac{5 \sigma(2-v)}{2 \mu e_{o}(7-5 v)}\right), \\
& Z_{\text {unaligned }}=z_{i}\left(1-\frac{5 \sigma(1+v)}{2 \mu e_{o}(7-5 v)}\right),
\end{aligned}
$$

where $\mu$ is the shear modulus, $v$ is Poisson's ratio, $z_{i}$ the interstitial bias for the dislocation in a stress-free lattice and $e_{o}$ is the stress relaxation volume induced by the defect. 
Since the defect concentrations are proportional to the dose rate, the dose rate dependence of the creep rate for both SIPA and PAG is also linear. The temperature dependence of the diffusion coefficient $D_{i}$ cancels the temperature dependence of the reaction rate constants causing both PAG and SIPA to have no temperature dependence. In previous work by Savino [26], [32], the stress induced anisotropic sink strength $\Delta Z_{i}$ was found to be a linear function of stress, making the SIPA mechanism linear in stress dependence and PAG quadratic in stress dependence.

By equating equations (4) and (5), the stress at which the PAG contribution exceeds that of SIPA can be determined:

$$
\sigma_{P A G / S I P A}=\frac{E b}{2}\left(\frac{L}{\pi}\right)^{1 / 2},
$$

For FM steels, $E$ is around 200GPa, $L$ is typically on the range of $1 \times 10^{10} \mathrm{~cm}^{-2}$ and $b$ around $2 \times 10^{-8} \mathrm{~cm}[8]$. Then PAG should overtake SIPA at stresses above $112 \mathrm{MPa}$. However, this calculation assumes the same amount of dislocations participate in both SIPA and PAG. Due to the anisotropic microstructure, more dislocations may prefer to climb or glide depending on the orientation and the stress state of the sample. Therefore, $112 \mathrm{MPa}$ is likely not the precise stress upon which PAG overtakes SIPA. However, this calculation does confirm that both mechanisms could be operating under the stress conditions (100-200MPa) of this study.

Both linear and quadratic fits were made to the PLB- and anisotropic loopadjusted strain rates to determine whether SIPA or PAG was dominating. The fits were forced through zero since irradiation creep goes to zero in the absence of stress. Figure 14 plots the creep strain rates, adjusted for PLB and anisotropic loop strain, as a function of stress. The plot shows that a linear fit goes through the majority of the data well within 
the experimental error, suggesting the experimental data can be explained by a linear stress dependence. Similarly, the quadratic fit also falls within the experimental error of the irradiation creep data. The analysis of the stress dependence suggests that both SIPA and PAG are viable irradiation creep mechanisms for FM steels.

The observation of anisotropic dislocation loop distribution would suggest SIPA is indeed operating during irradiation creep but is insufficient to account for majority of the strain rate at high stress. Gelles [33] and Wolfer [34] have both discussed the possibility of dislocation loops growing and interacting with dislocation networks under the influence of stress-induced anisotropic absorption of defects. Woo [5], [6] also expanded on the SIPA mechanism to include the climb of anisotropic dislocation network as a deformation mechanism. Despite the small direct contribution to strain by anisotropic dislocation loops, a combination of the anisotropic microstructure with dislocation climb and glide offer the mechanistic explanation that is most consistent with past observations and with this study. In light of this evidence, a combination of SIPA and PAG is the likely cause of irradiation creep in FM steels.

\section{Conclusion}

Irradiation creep of alloy T91 exhibited a linear dose rate dependence, power law stress dependence, and negligible temperature dependence. The dose rate dependence and temperature dependence were consistent with neutron irradiation creep under the same conditions. The stress dependence at low stress was also consistent with neutron irradiation creep experiments. The strain rates from proton irradiation creep experiments were found to be $\sim 100 \mathrm{x}$ higher than those in reactor experiments due to differences in creep regime, damage morphology, and sample thickness. 
The non-zero dose rate dependence and lack of temperature dependence from this experiment suggested that a thermally driven process, such as preferential emission, was not the dominant irradiation creep mechanism. Power law stress dependence provided evidence that power law breakdown dominates creep behavior at high stress.

The anisotropic dislocation loop density observed following proton irradiation creep accounted for only $4 \%-11 \%$ of the total irradiation creep strain. Adjusting the measured creep rates for strain due to the anisotropic loop distribution and power law breakdown showed agreement with the stress dependence predicted by both SIPA and PAG irradiation creep mechanisms. Over the conditions of this study, the likely mechanisms governing irradiation creep in F-M steel is a combination of SIPA and PAG.

\section{Acknowledgements}

The authors gratefully acknowledge Ovidiu Toader and Fabian Naab for their assistance in conducting proton irradiations, and Lumin Wang, Kai Sun and Scott Braswell for their assistance in TEM analysis. Micah Hackett for his helpful discussion and insights. The authors also acknowledge the facilities provided by the Michigan Ion Beam Laboratory, the Electron Microbeam Analysis Laboratory at University of Michigan, and Nanotech User Facility at University of Washington. Support for this research was provided by the Department of Energy under award NERI 08-055 DEFG07-07ID14894. 


\section{References}

[1] J. . Matthews and M. . Finnis, "Irradiation Creep Models - An Overview," J. Nucl. Mater., vol. 159, pp. 257-285, 1988.

[2] F. A. Garner and D. S. Gelles, "Irradiation Creep Mechanisms: An Experimental Perspective,” J. Nucl. Mater., vol. 159, pp. 286-309, 1988.

[3] R. . Klueh and D. . Harris, High Chromium Ferritic Martensitic Materials for Nulcear Applications. ASTM International, 2001, p. 221.

[4] C. H. Woo and F. A. Garner, "A SIPA-based theory of irradiation creep in the low swelling rate regime," J. Nucl. Mater., vol. 194, pp. 1309-1312, 1992.

[5] C. H. Woo, "Irradiation creep due to climb-induced glide in an anisotropic dislocation structure," J. Nucl. Mater., vol. 98, pp. 295-305, 1981.

[6] C. H. Woo, "Effects of an Anisotropic Dislocation Structure on Irradiation due to SIPA,” J. Nucl. Mater., vol. 80, pp. 132-143, 1979.

[7] L. K. Mansur and T. C. Reiley, "Irradiation creep by dislocation glide enabled by preferred absorption of point defects - theory and experiment," J. Nucl. Mater., vol. 90, pp. 60-67, 1980.

[8] L. K. Mansur, "Irradiation creep by climb-enabled glide of dislocations resulting from preferred absorption of point defects," Philos. Mag., vol. 39, p. 497, 1979.

[9] C. Xu and G. S. Was, "In situ proton irradiation creep of ferritic-martensitic steel T91," J. Nucl. Mater., vol. 441, no. 1-3, pp. 681-687, 2013.

[10] J. F. Ziegler, J. P. Biersack, and M. D. Ziegler, “SRIM 2008.” 2008.

[11] K. Kroupa, "Dislocation Loops," in Theory of Crystal Defects - Proceedings of the Summer School held in Hrazany in September 1964, 1966, pp. 308-313.

[12] C. Xu and G. S. Was, "Anisotropic Dislocation Loop Distribution in Alloy T91 during Irradiation Creep," J. Nucl. Mater., 2014.

[13] J. Chen, P.Jung, and W. Hoffelner, "Irradiation creep of Candidate Material for Advanced Nuclear Plants,” J. Nucl. Mater., 2013.

[14] J. Chen, M. a. Pouchon, a. Kimura, P. Jung, and W. Hoffelner, "Irradiation creep and microstructural changes in an advanced ODS ferritic steel during helium implantation under stress," J. Nucl. Mater., vol. 386-388, pp. 143-146, Apr. 2009. 
[15] B. A. Chin, “Topical Conference on Ferritic Steels for Use in Nuclear Energy Technologies," in The Metallurtical Society of AIME, 1984, p. 593.

[16] M. L. Grossbeck, K. Ehrlich, and C. Wassilew, "An Assessment of tensile, irradiation creep, creep rupture, and fatigue behavior in austenitic stainless steels with emphasis on spectral effects," J. Nucl. Mater., vol. 174, 1990.

[17] G. S. Was, Fundamentals of Radiation Materials Science. Springer, 2007.

[18] M. B. Toloczko, F. A. Garner, and S. A. Maloy, "In-reactor Creep of Two Heats of T91 ( Modified 9Cr-1Mo ) from $\sim 400{ }^{\circ} \mathrm{C}$ to $600^{\circ} \mathrm{C}$," in 8th International Workshop on Spallation Materials Technology (IWSMT-8), 2006.

[19] M.B. Toloczko, F.A. Garner, and C.R. Eiholzer, "Irradiation creep and swelling of the US fusion heats of HT9 and $9 \mathrm{Cr}-1 \mathrm{Mo}$ to $208 \mathrm{dpa}$ at $400^{\circ} \mathrm{C}$," J.Nucl.Mater., vol. 212-215, 1994

[20] R. L. Klueh and a. T. Nelson, "Ferritic/martensitic steels for next-generation reactors," J. Nucl. Mater., vol. 371, no. 1-3, pp. 37-52, Sep. 2007.

[21] G. Gupta, "Irradiation Creep Behavior of Ferritic-martensitic Alloy T91 by Subgrain Boundary Desnity Enhancement," University of Michigan, 2007.

[22] E. M. Haney, F. Dalle, M. Sauzay, L. Vincent, I. Tournié, L. Allais, and B. Fournier, "Macroscopic results of long-term creep on a modified 9Cr-1Mo steel (T91),” Mater. Sci. Eng. A, vol. 510-511, pp. 99-103, Jun. 2009.

[23] M. Kassner, Fundamentals of Creep in Metals and Alloys, 2nd ed. Elsevier, 2009.

[24] K. Kimura, "Creep Deformation, rupture strength, and rupture ductility of grades T/P92 Steesl," ASME Symp. Elev. Temp. Appl. Mater. Foss. Nucl. Petrochemical Ind., 2014.

[25] S. J. Zinkle, J. P. Robertson, and R. L. Klueh, "Thermophysical and Mechanical Properties for Fe-(8-9)\%Cr Reduced Activation Steels," 1998.

[26] E. J. SAVINO and C. N. TOME, "Irradiation Creep by Stress-induced Preferential Attraction due to Anisotropic Diffsion (SIPA-AD)," J. Nucl. Mater., vol. 109, pp. 405-416, 1982.

[27] G. Gupta and G. S. Was, "Improved Creep Behavior of Ferritic-Martensitic Alloy T91 by Subgrain Boundary Density Enhancement," Metall. Mater. Trans. A, vol. 39, no. 1, pp. 150-164, Dec. 2007.

[28] J. J. Penisten, "The Mechanism of Radiation-induced Segregation in FerriticMartensitic Steels," University of Michigan, 2012. 
[29] A. D. Brailsford and L. K. Mansur, "The Effect of Precipitate-Matrix Interface Sinks on the Growth of Voids in the Matrix," J. Nucl. Mater., vol. 104, pp. 1403$1408,1981$.

[30] B. A. Chin, "An Analysis of the Creep Properties of a 12Cr-1Mo-W-V Steel," in Topical Conference on Ferritic Alloys for Use in Nuclear Energies Technologies, 1984.

[31] A. Kohyama, "Irradiation Creep of Low-Activation Ferritic Steels in FFTF/MOTA," J. Nucl. Mater., vol. 212, pp. 751-754, 1994.

[32] E. J. Savino, "Stress-induced Preferred Absorption Due to Saddle-point," J. Nucl. Mater., vol. 116, pp. 17-28, 1983.

[33] D. S. Gelles, "Effects of stress on microstructural evolution during irradiation.," $J$. Nucl. Mater., vol. 5, pp. 146-161, 1993.

[34] W. G. Wolfer, "Correlation of radiation creep theory with experimental evidence," J. Nucl. Mater., vol. 90, pp. 175-192, 1980. 
TABLES

Table 1. Percent weight composition of T91

\begin{tabular}{|c|c|c|c|c|c|c|c|}
\hline & $\mathrm{Cr}$ & $\mathrm{Mo}$ & $\mathrm{Mn}$ & $\mathrm{Si}$ & $\mathrm{V}$ & $\mathrm{Ni}$ & $\mathrm{Cu}$ \\
\hline $\mathrm{Wt} \%$ & 8.37 & 0.9 & 0.45 & 0.28 & 0.22 & 0.21 & 0.17 \\
\hline $\mathrm{At} \%$ & 8.89 & 0.52 & 0.45 & 0.55 & 0.23 & 0.20 & 0.15 \\
\hline & $\mathrm{C}$ & $\mathrm{Nb}$ & $\mathrm{Al}$ & $\mathrm{N}$ & $\mathrm{P}$ & $\mathrm{S}$ & $\mathrm{Fe}$ \\
\hline $\mathrm{Wt} \%$ & 0.1 & 0.076 & 0.022 & 0.048 & 0.009 & 0.003 & $\mathrm{Bal}$ \\
\hline $\mathrm{At} \%$ & 0.05 & 0.045 & 0.045 & 0.189 & 0.016 & 0.005 & $\mathrm{Bal}$ \\
\hline
\end{tabular}

Table 2. Strain rate results of irradiation creep experiments.

\begin{tabular}{|c|c|c|c|c|c|c|}
\hline $\begin{array}{c}\text { Sample } \\
\text { Name }\end{array}$ & $\begin{array}{c}\text { Temperature } \\
\left({ }^{\circ} \mathrm{C}\right)\end{array}$ & $\begin{array}{c}\text { Stress } \\
(\mathrm{MPa})\end{array}$ & $\begin{array}{c}\text { Dose Rate } \\
(\mathrm{dpa} / \mathrm{s})\end{array}$ & $\begin{array}{c}\text { Dose } \\
(\mathrm{dpa})\end{array}$ & $\begin{array}{c}\text { Strain Rate } \\
\left(10^{-9} \mathrm{~s}^{-1}\right)\end{array}$ & Error $\left(10^{-9} \mathrm{~s}^{-1}\right)$ \\
\hline IT450200-A & 450 & 200 & $1.7 \times 10^{-6}$ & 0.5 & 12.5 & 4.46 \\
\hline IT450200-B & 450 & 200 & $1.7 \times 10^{-6}$ & 0.5 & 11.5 & 4.46 \\
\hline IT450180-A & 450 & 180 & $1.7 \times 10^{-6}$ & 0.5 & 4.67 & 1.47 \\
\hline IT450180-B & 450 & 180 & $1.7 \times 10^{-6}$ & 0.5 & 5.00 & 1.47 \\
\hline IT450160-A & 450 & 160 & $1.7 \times 10^{-6}$ & 0.5 & 2.7 & 1.35 \\
\hline IT450140-A & 450 & 140 & $1.7 \times 10^{-6}$ & 0.5 & 2.05 & 1.02 \\
\hline IT450120-A & 450 & 120 & $1.7 \times 10^{-6}$ & 0.5 & 1.9 & 0.95 \\
\hline IT450100-A & 450 & 100 & $1.7 \times 10^{-6}$ & 1 & 1.67 & 0.83 \\
\hline IT450000-A & 450 & 0 & $1.7 \times 10^{-6}$ & 0.5 & $\mathrm{~N} / \mathrm{A}$ & $\mathrm{N} / \mathrm{A}$ \\
\hline IT400160-A & 400 & 160 & $1.4 \times 10^{-6}$ & 0.5 & $\sim 2.9$ & 1.45 \\
\hline IT500180-A & 500 & 180 & $5 \times 10^{-6}$ & 0.5 & 5.78 & 2.89 \\
\hline IT500160-A & 500 & 160 & $* 1.5 \times 10^{-6}$ & 0.8 & 1.78 & 0.89 \\
\hline IT500160-A & 500 & 160 & $* 1.7 \times 10^{-6}$ & 0.4 & 2.33 & 1.16 \\
\hline IT500160-A & 500 & 160 & $* 2.4 \times 10^{-6}$ & 0.6 & 5.08 & 2.54 \\
\hline TT450200-A & 450 & 200 & 0 & 0 & 1.38 & 0.69 \\
\hline TT500200-A & 500 & 200 & 0 & 0 & 12.8 & 5.80 \\
\hline TT500200-B & 500 & 200 & 0 & 0 & 11.5 & 5.80 \\
\hline IH450160-A & 450 & 160 & $1.7 \times 10^{-6}$ & 0.5 & 3.45 & 1.72 \\
\hline IA450160-A & 450 & 160 & $1.7 \times 10^{-6}$ & 0.5 & 5.85 & 2.92 \\
\hline
\end{tabular}

* Experiment conducted on the same sample at different conditions.

$\sim$ Experimental condition difficult to control due to low temperature. 
Table 3. Strain due to anisotropic loop density and measured total strain

\begin{tabular}{|c|c|c|c|c|c|}
\hline $\begin{array}{c}\text { Sample } \\
\text { Name }\end{array}$ & $\begin{array}{c}\text { Loop } \\
\text { Anisotropy } \\
\text { Strain (\%) }\end{array}$ & $\begin{array}{c}\text { Average Loop } \\
\text { Size (nm) }\end{array}$ & $\begin{array}{c}\text { Dislocation } \\
\text { Loop Density } \\
\left(\mathrm{m}^{-3}\right)\end{array}$ & $\begin{array}{c}\text { Measured } \\
\text { Total Strain } \\
(\%)\end{array}$ & $\begin{array}{c}\text { Percent of } \\
\text { Strain due to } \\
\text { Anisotropy (\%) })\end{array}$ \\
\hline IT450100 & 0.006 & 24.3 & $1.6 \times 10^{21}$ & 0.10 & 6 \\
\hline IT450180 & 0.0056 & 24.9 & $1.3 \times 10^{21}$ & 0.13 & 4.3 \\
\hline IT450200 & 0.0158 & 42.3 & $1.0 \times 10^{21}$ & 0.36 & 4.4 \\
\hline IT500180 & 0.0067 & 23.3 & $1.5 \times 10^{21}$ & 0.06 & 11.2 \\
\hline
\end{tabular}


Table 4. Input parameters for calculation of point defect concentrations.

\begin{tabular}{|c|c|c|c|}
\hline \multicolumn{4}{|c|}{ Constant Inputs } \\
\hline Parameter & Value & Units & Notes \\
\hline $\mathrm{T}$ & $400-500$ & ${ }^{\circ} \mathrm{C}$ & Irradiation temperature \\
\hline$\sigma$ & $100-200$ & $\mathrm{MPa}$ & Applied stress \\
\hline $\mathrm{K}_{\mathrm{o}}$ & $0-5 \times 10^{-6}$ & $\mathrm{dpa} / \mathrm{s}$ & Irradiation dose rate \\
\hline$\Omega$ & $1.23 \times 10^{-23}$ & $\mathrm{~cm}^{3} /$ atom & Atomic volume \\
\hline $\mathrm{k}$ & $1.38 \times 10^{-23}$ & $\mathrm{~Pa} / \mathrm{K}$ & Boltzmann constant \\
\hline $\mathrm{e}_{\mathrm{o}}$ & 0.8 & N/A & Interstitial relaxation volume [31] \\
\hline$v$ & 0.33 & N/A & Poisson's Ratio \\
\hline$\mu$ & $75 \times 10^{3}$ & $\mathrm{MPa}$ & Shear modulus \\
\hline $\mathrm{E}$ & $200 \times 10^{3}$ & $\mathrm{MPa}$ & Elastic modulus \\
\hline$\overline{Z_{\mathrm{i}}}$ & 1.02 & N/A & $\begin{array}{c}\text { Dislocation bias for interstitials } \\
{[31]}\end{array}$ \\
\hline $\mathrm{z}_{\mathrm{v}}$ & 1 & N/A & Dislocation bias for vacancies [31] \\
\hline $\mathrm{E}_{\mathrm{if}}$ & 4.6 & $\mathrm{eV}$ & Interstitial formation energy [27] \\
\hline$\overline{E_{\mathrm{vf}}}$ & 1.7 & $\mathrm{eV}$ & Vacancy formation energy [27] \\
\hline $\mathrm{E}_{\mathrm{im}}$ & 0.2 & $\mathrm{eV}$ & Interstitial migration energy [27] \\
\hline $\mathrm{E}_{\mathrm{vm}}$ & 0.67 & $\mathrm{eV}$ & Vacancy migration energy [27] \\
\hline \multicolumn{4}{|c|}{ Measured Inputs: IT 450200} \\
\hline $\mathrm{d}$ & 0.45 & $\mu \mathrm{m}$ & Sub-grain size \\
\hline $\mathrm{R}_{\mathrm{ppt}}$ & 0.16 & $\mu \mathrm{m}$ & Average precipitate radius [27] \\
\hline $\mathrm{C}_{\mathrm{gb}}$ & $2.1 \times 10^{13}$ & $\mathrm{~cm}^{-3}$ & Sub-grain density \\
\hline $\mathrm{C}_{\text {loop }}$ & $1.35 \times 10^{10}$ & $\mathrm{~cm}^{-2}$ & Dislocation loop line density \\
\hline $\mathrm{C}_{\text {network }}$ & $5.7 \times 10^{10}$ & $\mathrm{~cm}^{-2}$ & Dislocation network line density \\
\hline $\mathrm{C}_{\mathrm{ppt}}$ & $1.16 \times 10^{14}$ & $\mathrm{~cm}^{-3}$ & Precipitate density [27] \\
\hline $\mathrm{k}_{\mathrm{ppt}}$ & $1.4 \times 10^{11}$ & $\mathrm{~cm}^{-2}$ & Precipitate sink strength \\
\hline $\mathrm{k}_{\mathrm{gb}}$ & $7.4 \times 10^{10}$ & $\mathrm{~cm}^{-2}$ & Sub-grain sink strength \\
\hline $\mathrm{k}_{\text {loop }}$ & $6.9 \times 10^{10}$ & $\mathrm{~cm}^{-2}$ & Dislocation loop sink strength \\
\hline
\end{tabular}




\begin{tabular}{|c|c|c|c|}
\hline $\mathrm{k}_{\text {network }}$ & $4.4 \times 10^{11}$ & $\mathrm{~cm}^{-2}$ & Dislocation network sink strength \\
\hline $\mathrm{k}_{\mathrm{total}}$ & $7.3 \times 10^{11}$ & $\mathrm{~cm}^{-2}$ & Total sink strength \\
\hline $\mathrm{K}_{\mathrm{is}} \mathrm{C}_{\mathrm{s}}$ & $2.4 \times 10^{6}$ & $\mathrm{~s}^{-1}$ & $\begin{array}{c}\text { Total reaction rate of interstitials } \\
\text { to sinks }\end{array}$ \\
\hline $\mathrm{K}_{\mathrm{vs}} \mathrm{C}_{\mathrm{s}}$ & $6.7 \times 10^{5}$ & $\mathrm{~s}^{-1}$ & $\begin{array}{c}\text { Total reaction rate of vacancies to } \\
\text { sinks }\end{array}$ \\
\hline
\end{tabular}


Figures:

Figure 1. Schematic of irradiation creep sample and samples used for loop orientation analysis.

Figure 2 SRIM result of $3 \mathrm{MeV}$ proton beam incident on T91 target. Damage peak occurs around $37 \mu \mathrm{m}$ into the sample. Nominal sample thickness of $35 \mu \mathrm{m}$ was used to avoid the damage peak and any proton implantation.

Figure 3. Schematic of irradiation creep experimental facility.

Figure 4. Schematic of dislocation loop image method and geometry. The tensile direction is at an arbitrary angle to the $<001>$ image plane, and the angle between the loop normal vector to the tensile axis is defined as $\theta$.

Figure 5. Irradiation creep curve and creep experiment parameters for sample IT450180B. The experiment was conducted at $450^{\circ} \mathrm{C}$ with an applied stress of $180 \mathrm{MPa}$, and a dose rate of $1.7 \times 10^{-6} \mathrm{dpa} / \mathrm{s}$.

Figure 6. Dose rate dependence of irradiation creep strain rate for IT500160 and linear fit to the data. Sample IT500160 was irradiated at a temperature of $500^{\circ} \mathrm{C}$, and a stress of $160 \mathrm{MPa}$.

Figure 7. Temperature dependence of irradiation creep experiments done at $400^{\circ} \mathrm{C}, 450^{\circ} \mathrm{C}$, and $500^{\circ} \mathrm{C}$ at applied stress of $160 \mathrm{MPa}$ and dose rate of $1.7 \times 10^{-6} \mathrm{dpa} / \mathrm{s}$.

Figure 8. Stress dependence of irradiation creep rates of T91 at $450^{\circ} \mathrm{C}, 1.7 \times 10^{-6} \mathrm{dpa} / \mathrm{s}$ and the best line fits to the data.

Figure 9. TEM image of $a_{0}<100>$ edge-on loops with $g=<110>$ on the $<100>$ zone axis. a) IT450100, b) IT450180, c)IT500180, d)IT450200.

Figure 10. Loop anisotropy plot of the irradiation creep experiments for a) IT450100, b) IT450180, c) IT500180, d) IT450200 (taken from [12]). 
Figure 11. Neutron irradiation creep data of T91 by Tolockzo [18] plotted as a function of irradiation temperature.

Figure 12. Comparison of proton irradiation creep and neutron irradiation creep rates [18] adjusted for dose rate.

Figure 13. Calculation of point defect concentration as a function of temperature with measured sink densities of IT450200 shown in Table 4.

Figure 14. Stress dependence of proton irradiation creep rates without contribution from anisotropic dislocation loops and power law breakdown with linear and quadratic fits.

\section{FIGURES}
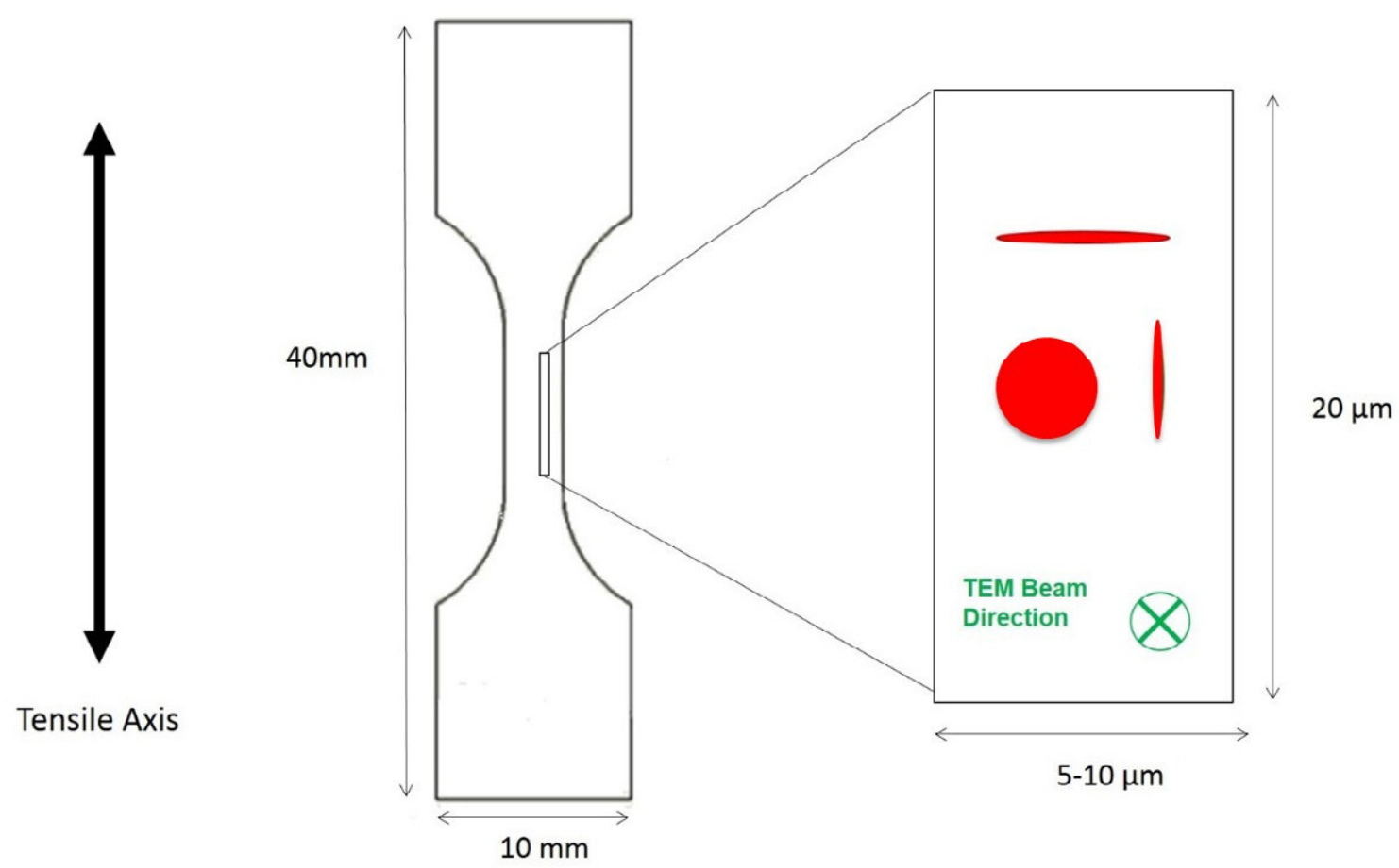

Fig 1 
Fig 2
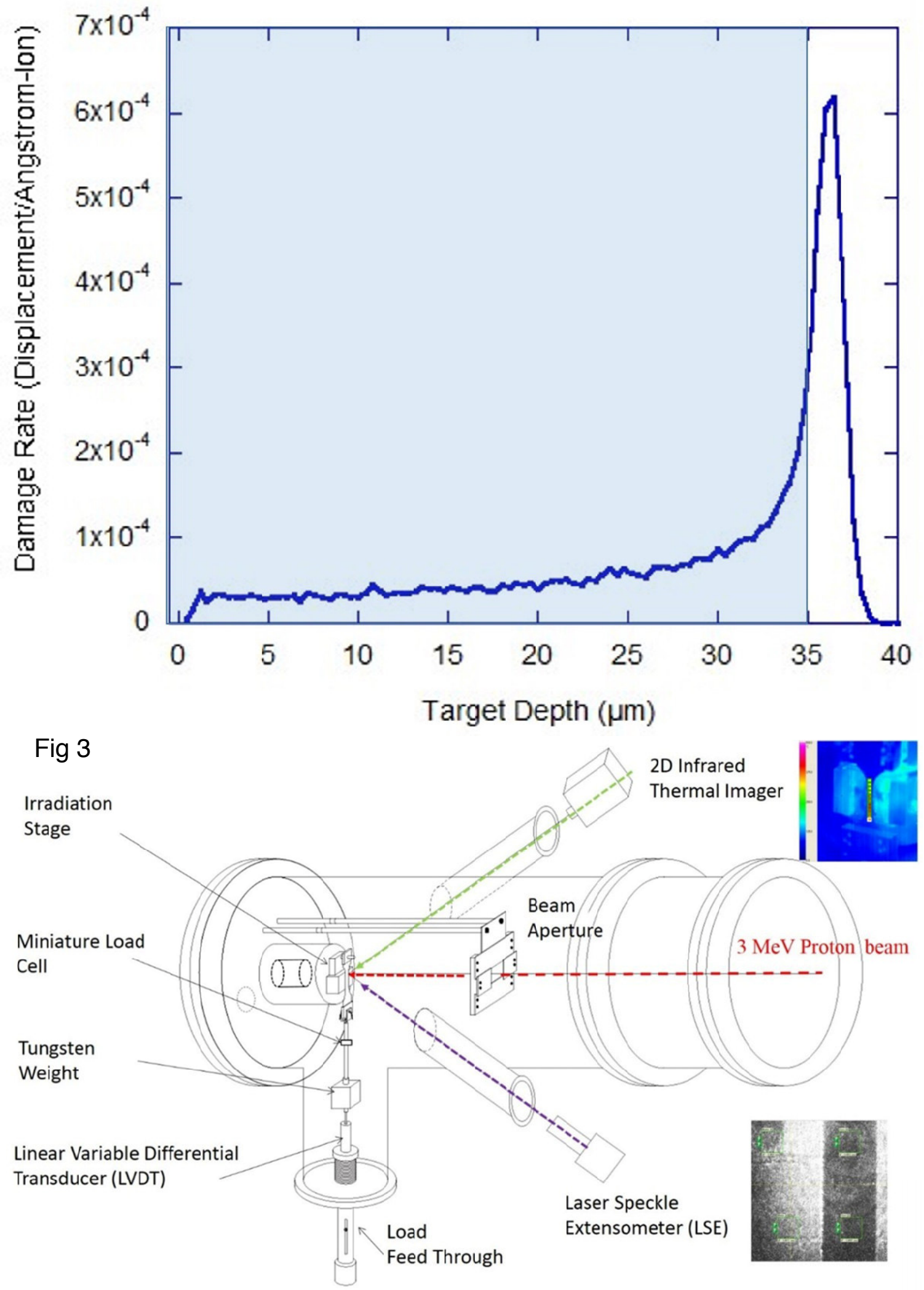


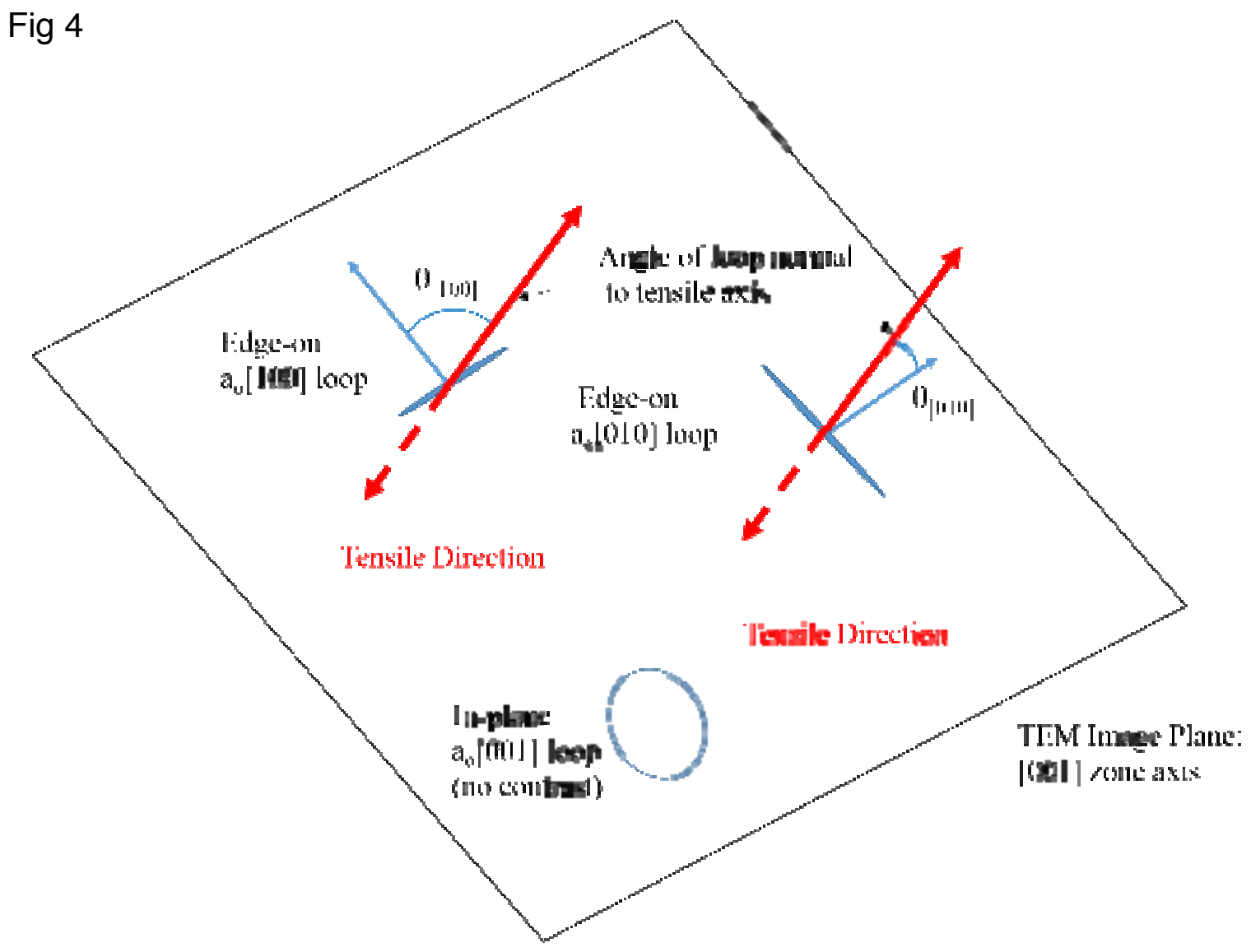


Fig 5

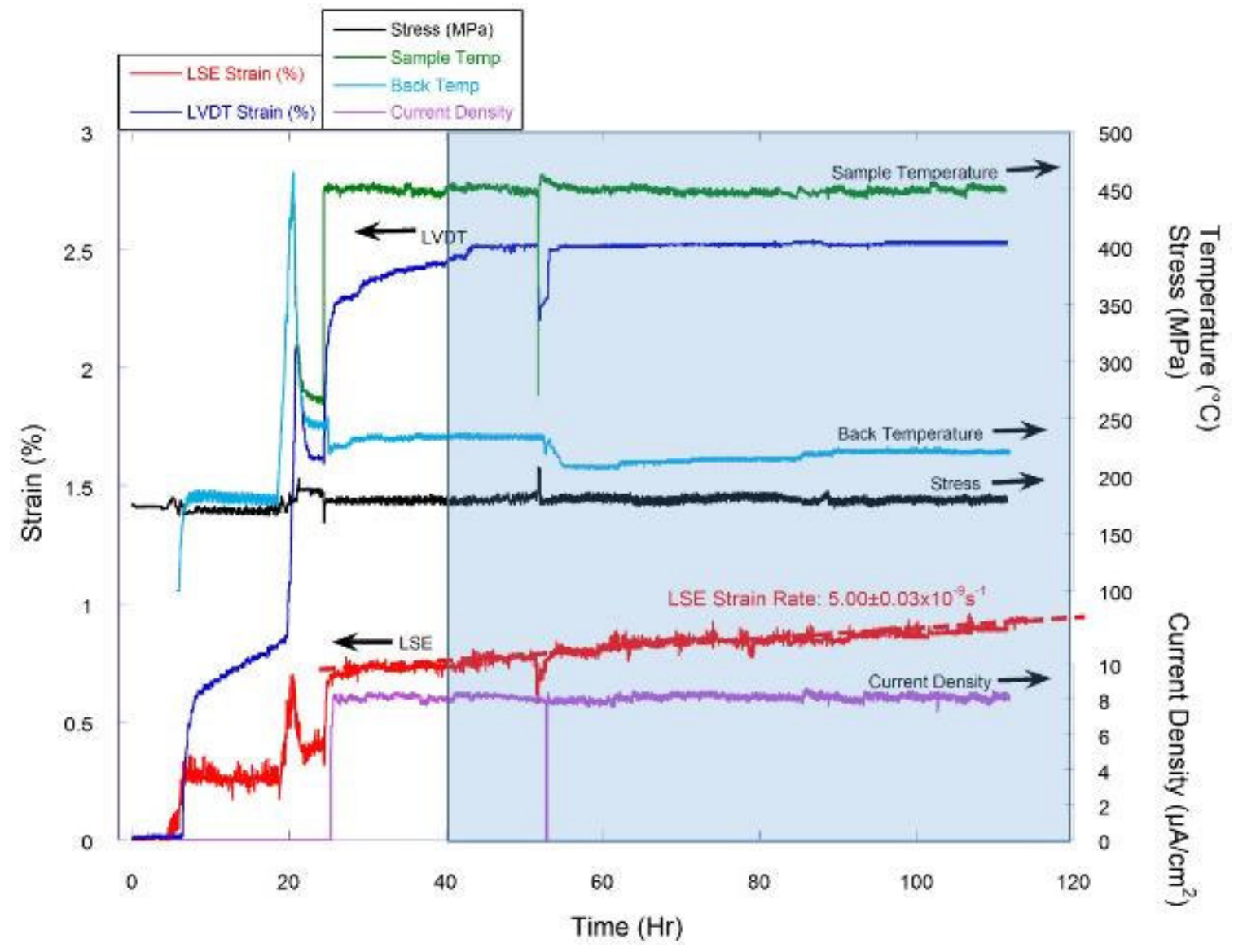


Fig 6

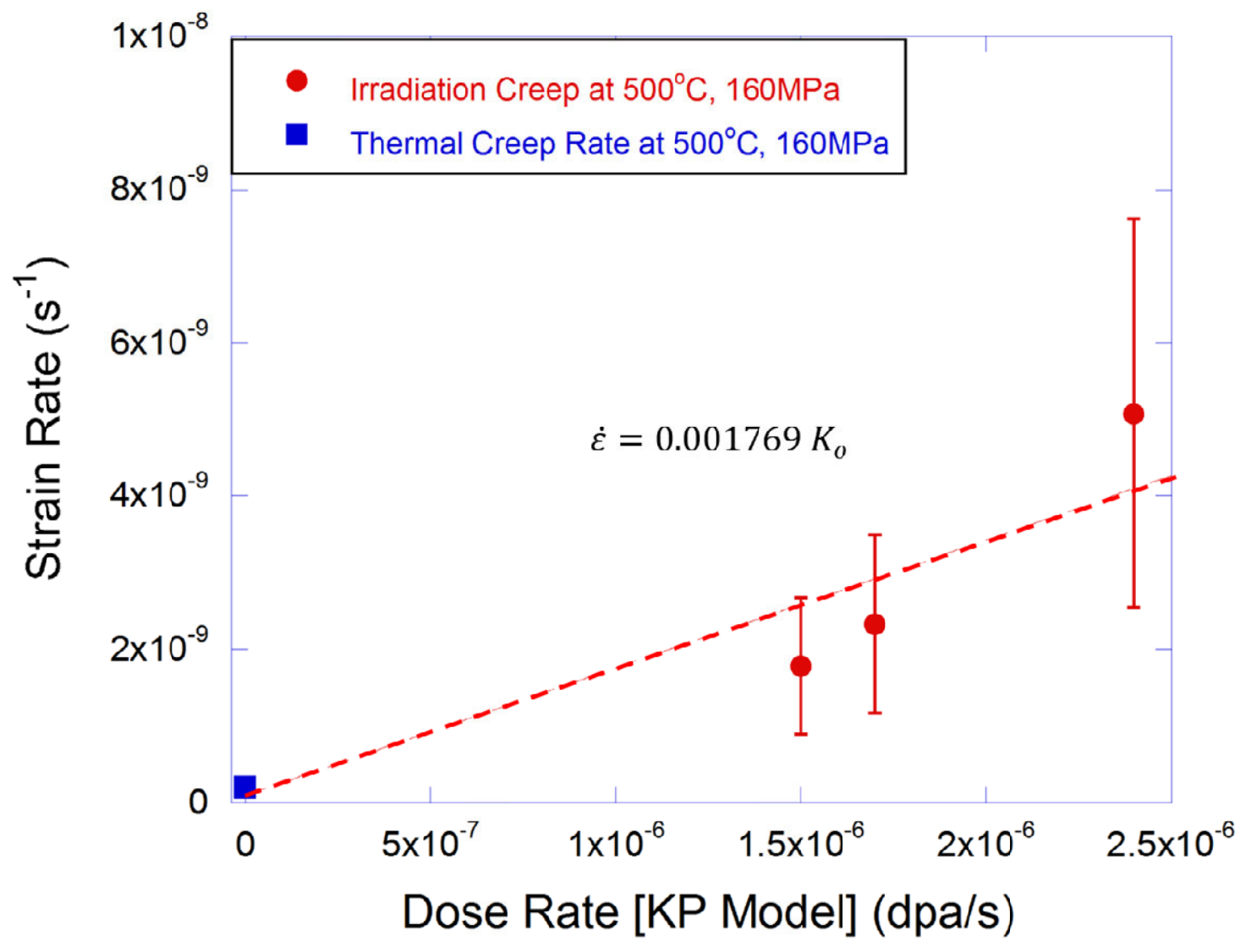


Fig 7

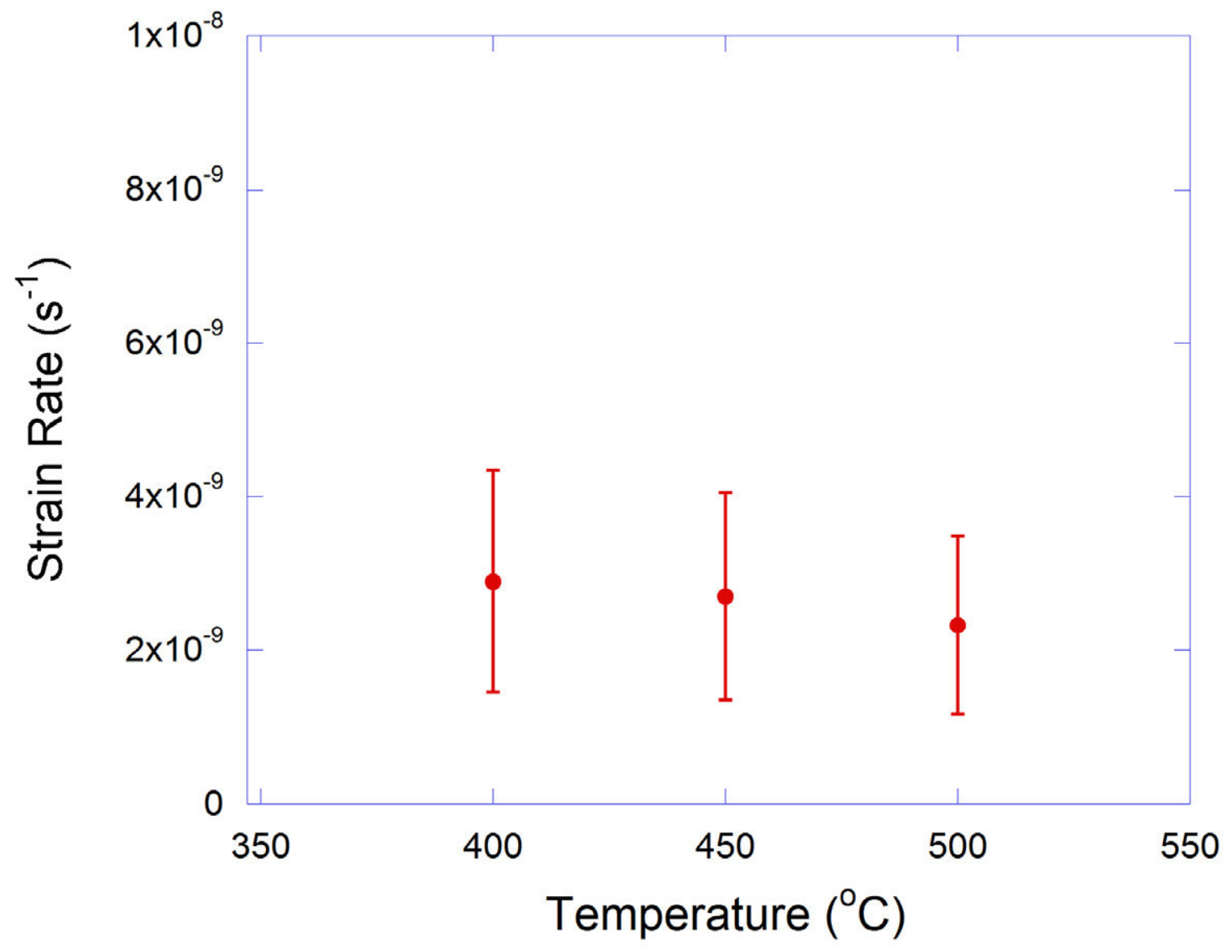


Fig 8

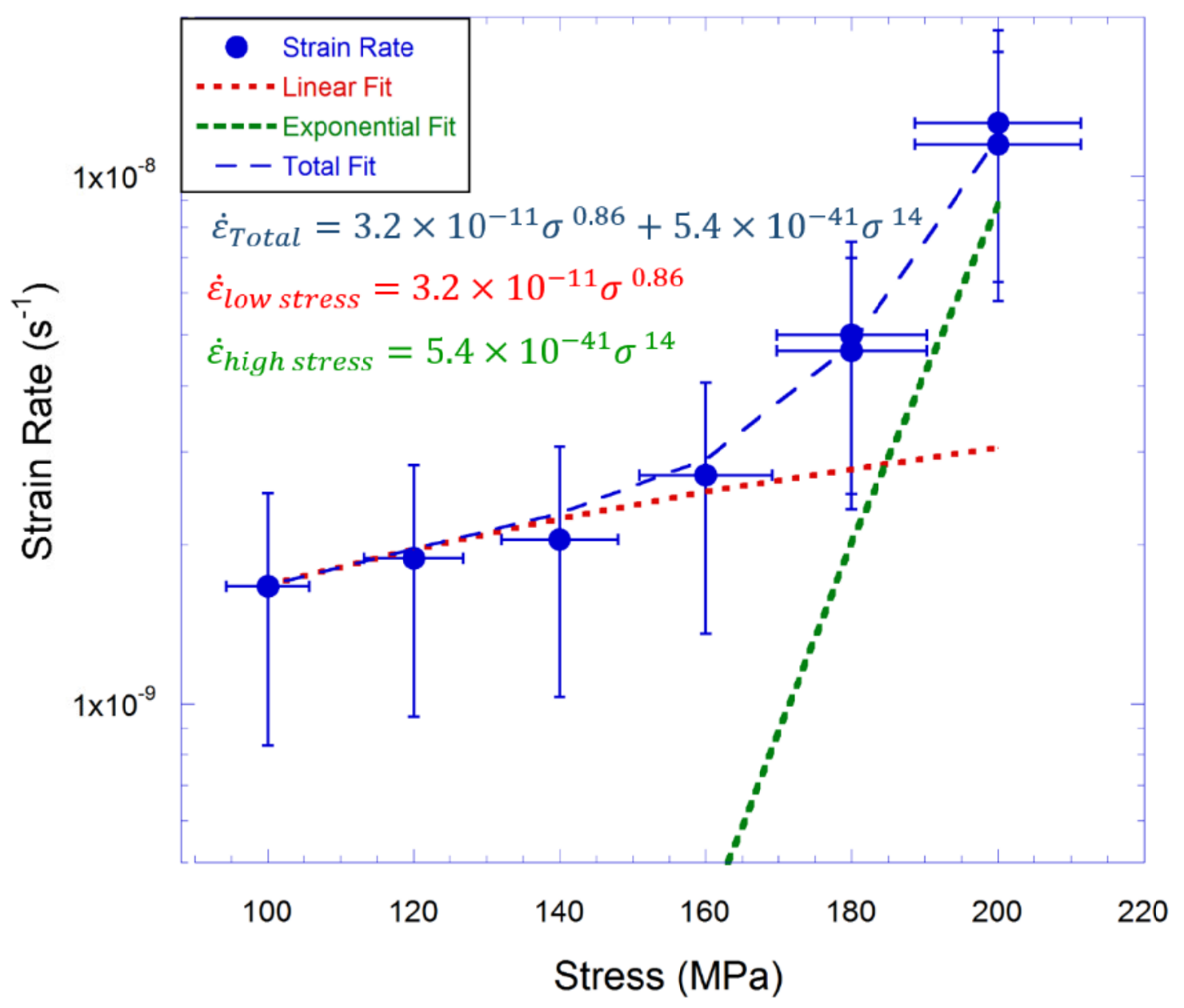


Fig9

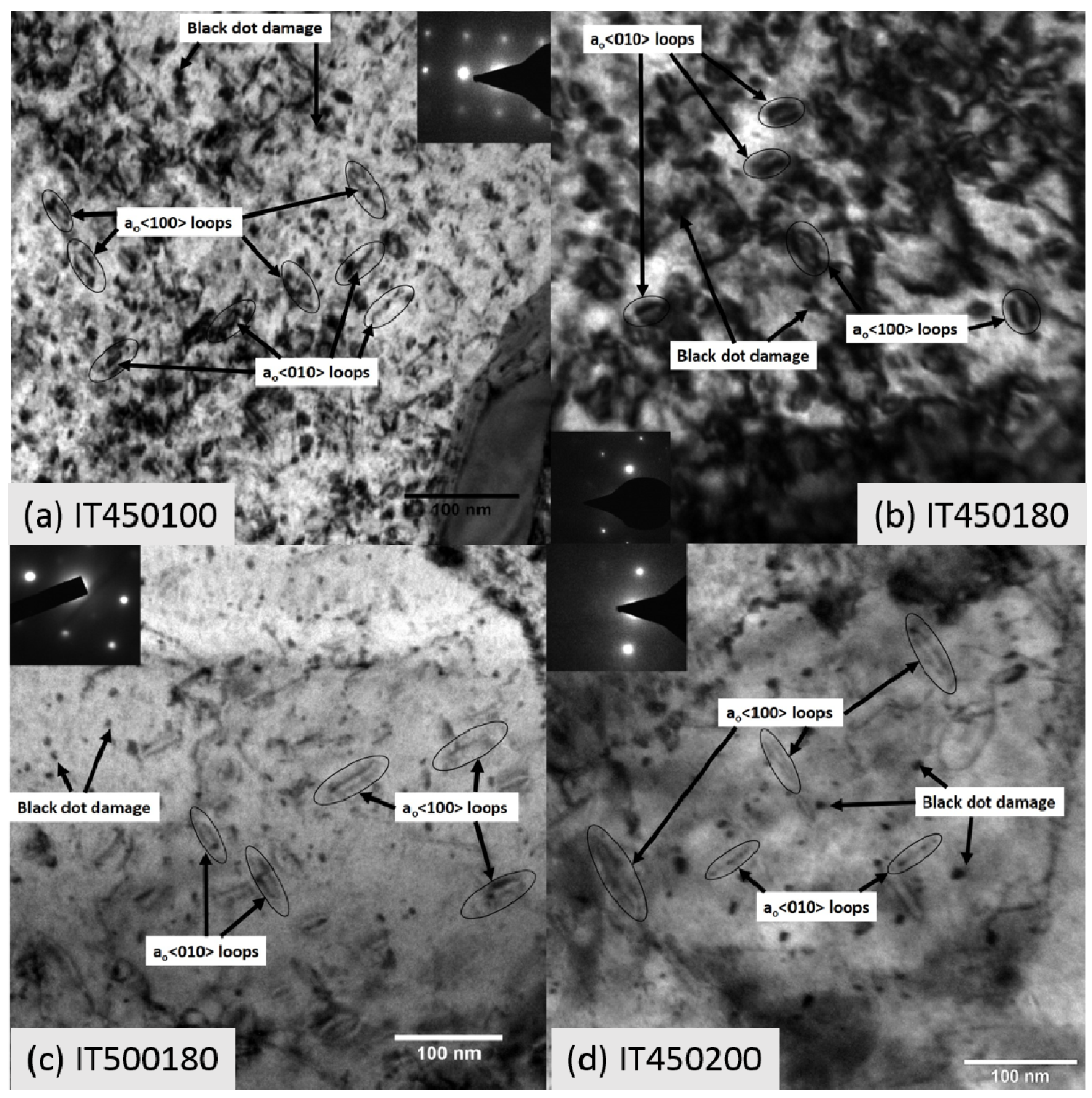


Fig 10
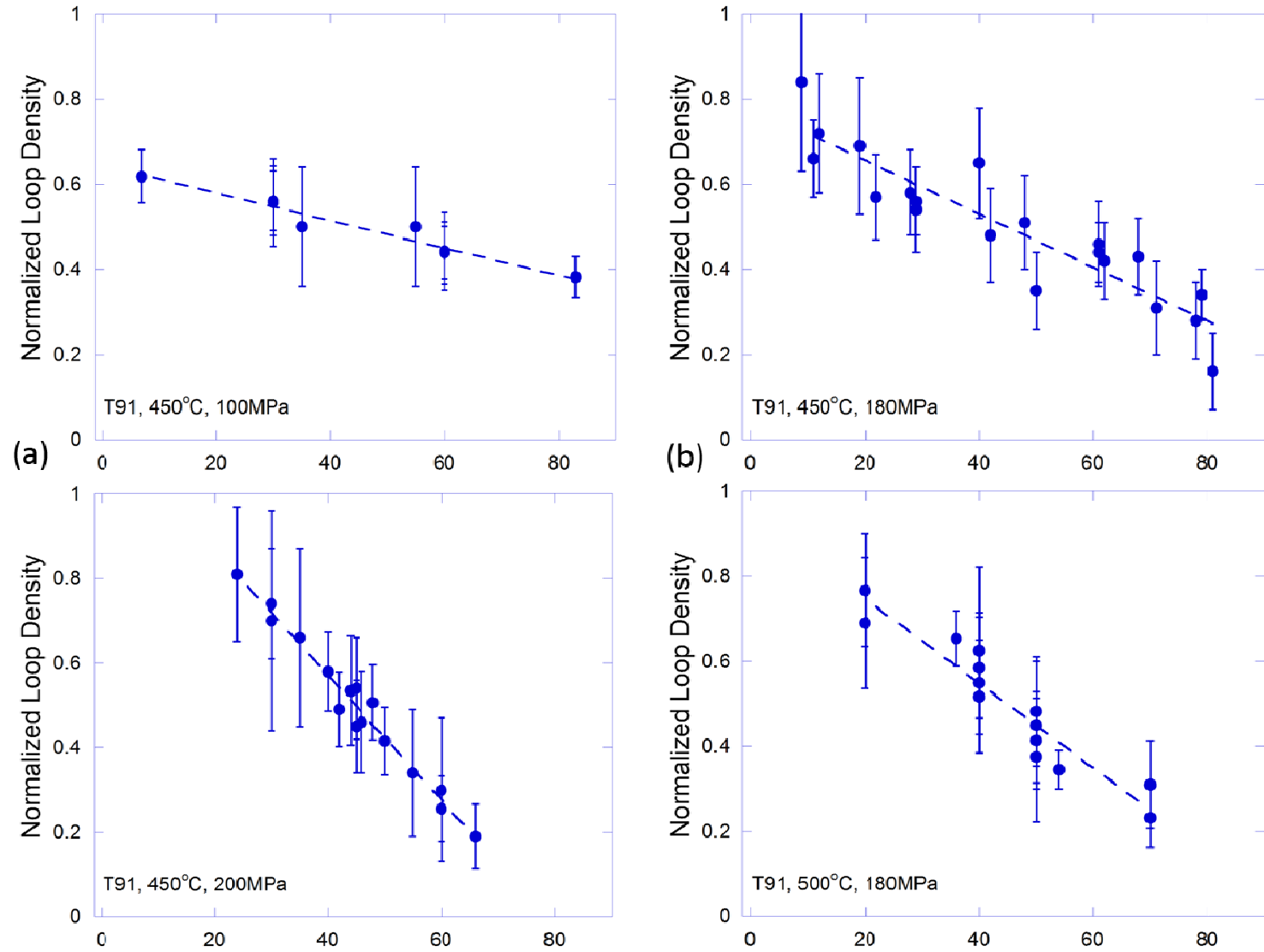

(c) Angle Between Loop Normal and Tensile Axis

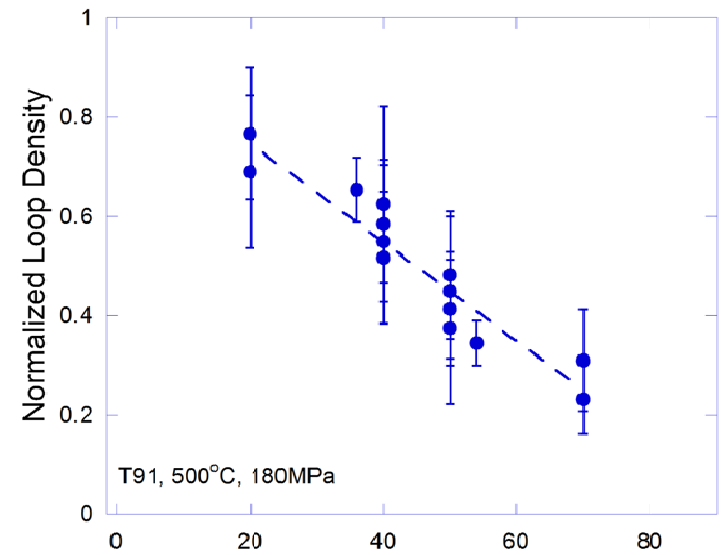

(d) Angle Between Loop Normal and Tensile Axis 
Fig 11

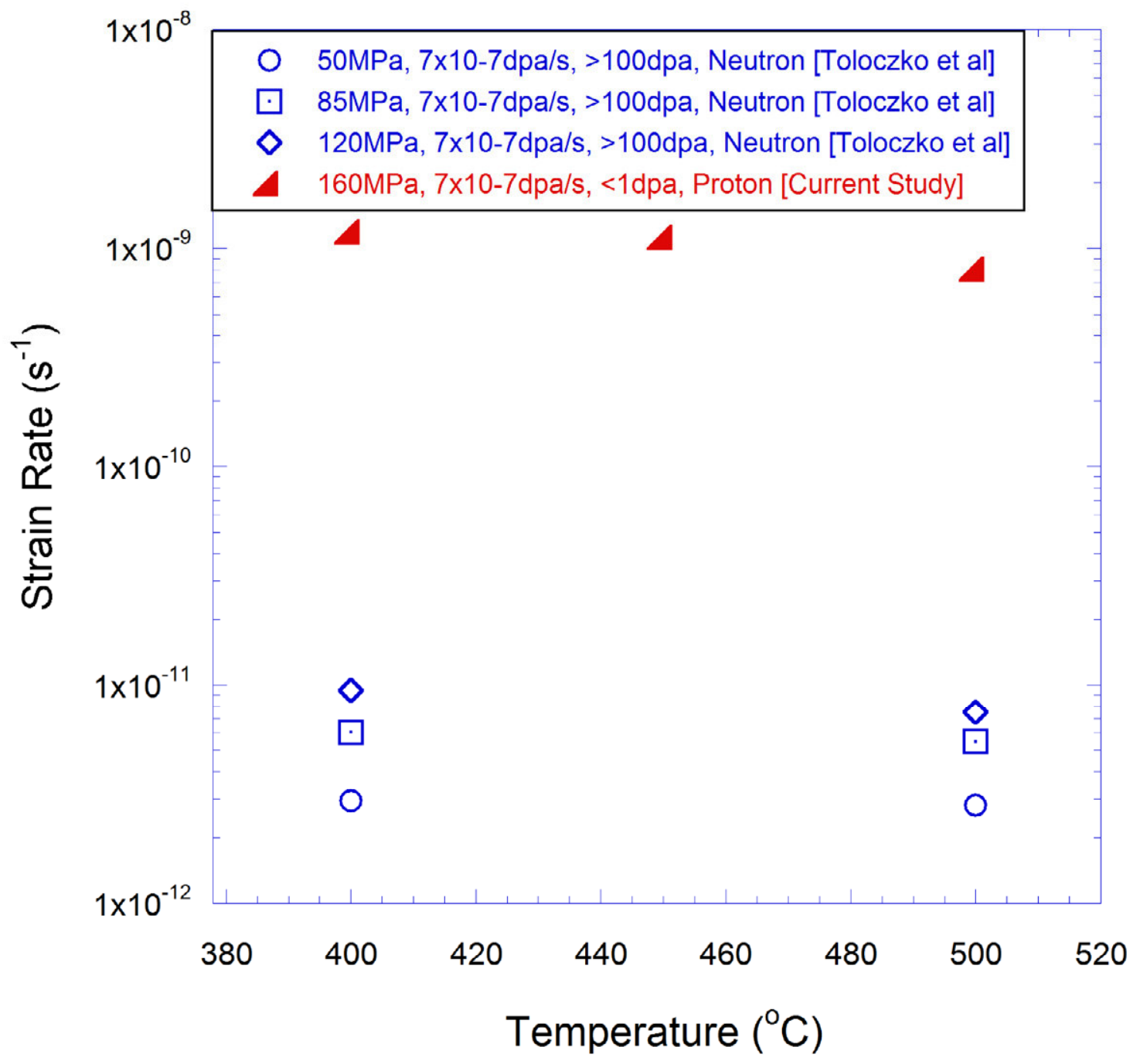


Fig 12

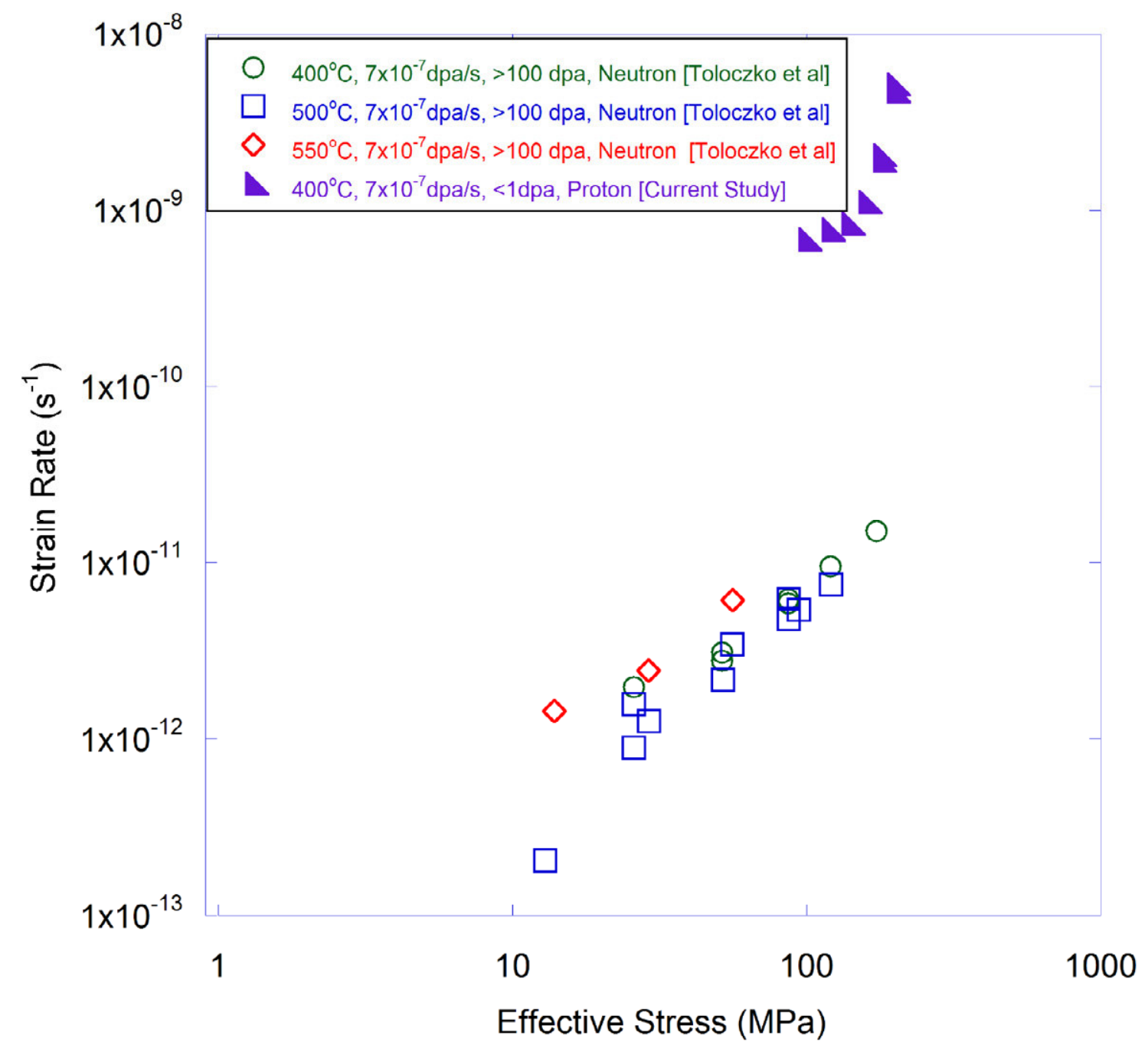


Fig 13

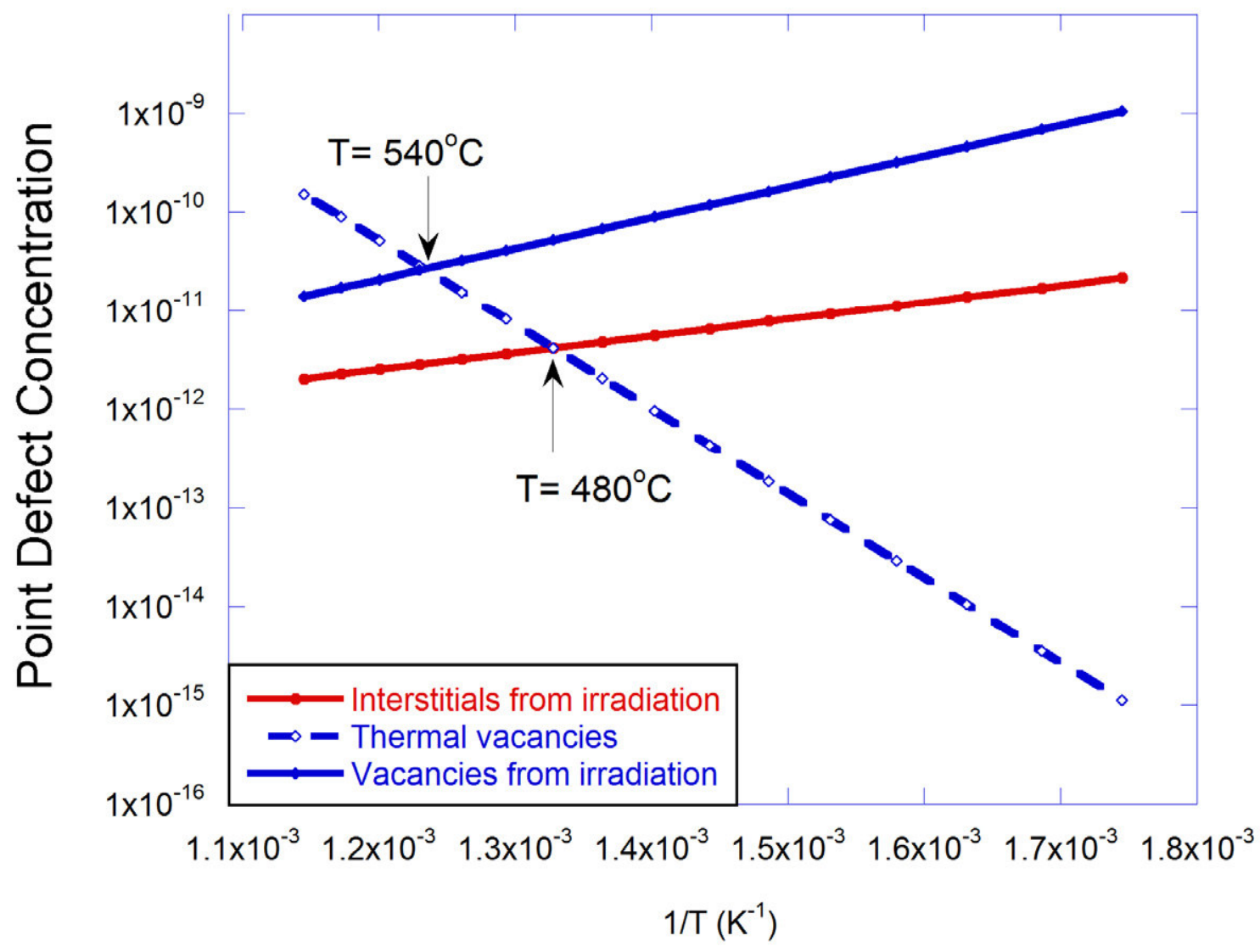


Fig 14

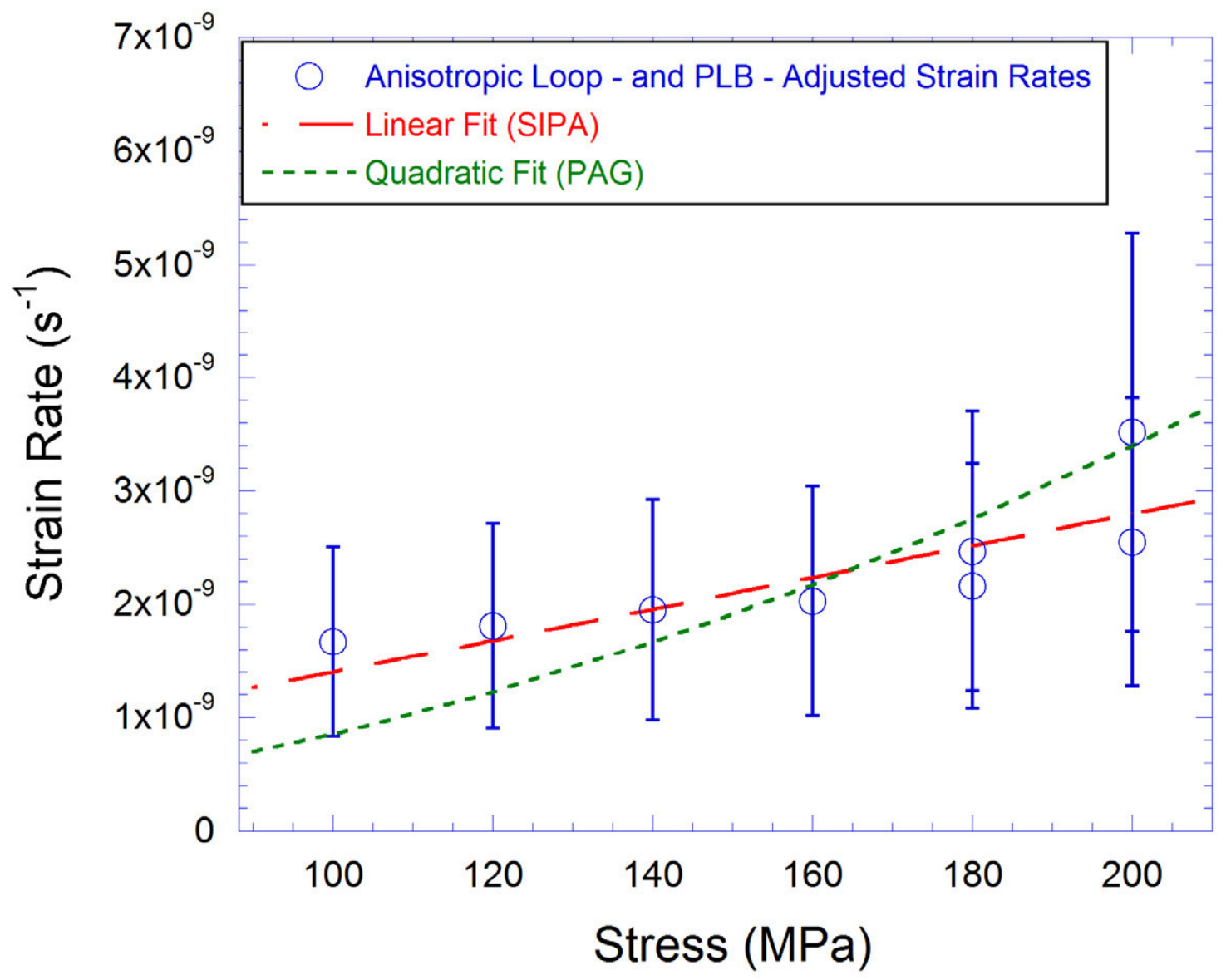

